Service a good deal of the research was contracted out, and the influence of such units as the MRC's Pneumoconiosis Research Unit was relatively large. But since 1969 the National Coal Board has established its own Institute of Occupational Medicine or, more accurately, perhaps, Mining Medicine, in which a number of diverse research groups have been brought together. This is the first report of the Institute. The research programme which is set out has a strong environmental bias, as is most appropriate. A good deal of the work is concerned with dust, and, as well as the standard equipment, the Institute possesses a wind tunnel. Some interesting findings are already beginning to appear, such as the relationship of dust exposure to radiological pneumoconiosis and a tentative answer to, perhaps, an even more important questionHow much dust can be breathed in without contracting pneumoconiosis? The resistance of some men to this condition is confirmed, and it is shown that in men under 45 years of age there is a definite association between exposure to respirable coal dust and the prevalence of bronchitis.

Some interesting work in ergonomics is going on and the acoustics team has shown how complicated the noise contours are round a piece of heavy machinery.

In its three years work the Institute has produced 29 publications and 36 technical memoranda. The report is nicely produced on art paper, and the photographs and reproductions reach a high standard.

\section{R. C. BROWNE}

Health Practice Research and Formalized Managerial Methods. By F. Grundy and W. A. Reinke. (Pp. 193; $£ 1 \cdot 25$.$) Geneva: WHO. 1972$.

The preface to this volume explains that its purpose is to 'describe, as simply as possible, the principles of health practice research and the managerial methods employed in tackling health practice problems'. The 'application of scientific and especially mathematical methods to management problems is relatively new'. The methods were used in relation to military problems during the second world war and subsequently in industry and commerce. More recently, WHO consultants have studied these techniques in relation to health practice research, and this volume is an expansion of their conclusions.

The first chapter on Scope and Character of Health Practice Research discusses techniques which will be well known to the occupational health physician-systems concepts, systems analysis, need-demand relationships, cost-benefit analysis, and the use of network and mathematical models. He will also appreciate the necessity of the multidisciplinary approach in health practice research, but the authors are correct in emphasizing this concept, not always sufficiently appreciated in other branches of our profession.

Chapter 2-The Methods of Operations Research Applied to Health Practice-is an expansion of the study of suitable models, especially of mathematical models, and proceeds to discuss decision analysis and dynamic programming.

These techniques are then used in studying various subjects in the next few chapters-Health Care in the Community; Disease Control, using typhoid fever, tuberculosis and cholera as examples; and Health Manpower Requirements. Further chapters consider training for health administration and health practice research.

There is also a useful annex on practical considerations in health practice research, which in a few pages gives excellent advice on many aspects of research planning. Those who try to introduce $d$ research element into their clinical or administrative work will find a very tidy outline for planning their research programme, so that this annex should be of interest to all occupational health physicians. While most of the book is concerned with general and hospital health services, occupational medicine could well profit from application of the principles enunciated. If we applied cost benefit analysis with adequate care to problems such as routine examinations and published our results, much good could result.

The authors have tackled a difficult subject with considerable success. They have enumerated their problems in the introduction, and their clarity here and in the subsequent chapters is perhaps the best recommendation of the techniques they describe.

They have chosen to give very few references in the text but have compiled a most useful annotated bibliography under seven subject groups. They and WHO are to be congratulated on such a fine presentation of their subject at such a low price.

M. A. CoOKE

Nutritional Deficiencies in Modern Society. Edited by Alan N. Howard and McLean Baird. (Pp. 109; illustrated; £1·30.) London: Newman Books. 1973.

Eight papers presented at a symposium arranged by the Food Education Society are published together in this small book. Those interested in current problems of nutrition will find this a useful and informed publication.

The prevalence of malnutrition in the United Kingdom is a question frequently raised in relation to vulnerable groups in the population. These papers, covering a wide variety of nutrients, form a useful series of reviews.

Dr. Callender, writing on iron deficiency anaemia, enumerates the sources of iron in the diet and describes some of the work carried out on absorption of this nutrient. While she concludes that iron deficiency is widespread, its incidence has been reduced by better medical care and higher standards of living.

Dr. Chanarin, discussing deficiencies of vitamin $\mathbf{B}_{12}$ and folic acid, reviews the literature on requirements and availability of these vitamins, indicating that groups at risk are likely to be found among strict vegetarians and possibly, in relation to folic acid deficiency, among pregnant women and elderly people.

Nutritional aspects of calcium and vitamin D are discussed by Professor Nordin. While nutritional rickets are rare in this country, he considers that calcium may be playing a significant role in the growth of children. He cites the increase in growth as seen in Japan and questions the effect that the removal of school milk might have on the development of children in the United Kingdom. This paper raises many questions in relation to calcium absorption, supplementation with vitamin $D$, 
and the requirement for calcium by different groups in the population. Dr. Exton Smith, writing on nutritional deficiences in the elderly, also raises the question of supplementation for this group.

Other nutrients discussed are vitamin C by Dr. Brook and some aspects of trace element nutrition in man by Dr. Mills. Copper, zinc, and chromium are selected for review. It is clear that little is known about requirements for these and other trace elements, but we have a useful review and many questions are raised which are as yet unanswered. The problems of assessing human diets are discussed by Dr. Mills in relation to trace elements and also by Mrs. Disselduff in connection with energy and other nutrients. There is further discussion on malnutrition due to malabsorption, in a paper by Dr. McLean Baird.

Thus, this publication covers several aspects of nutritional deficiencies, absorption, and levels of intake. The papers also raise many questions which will be debated by nutritionists for many years.

J. W. MARR

TUC Centenary Institute of Occupational Health Fourth Annual Report 1971/72. (Pp. 31.) Published by the London School of Hygiene \& Tropical Medicine, Keppel Street (Gower Street), London WC1. 1973.

It is always interesting for those engaged in the management of Occupational Health Services to see annual reports from other similar organizations, both to note progress and to compare achievement with their own services.

While the TUC Centenary Institute of Occupational Health is unique in this country the report is to some extent a barometer of the climate of progress in this field. A growth rate of $74 \%$ in the work of the Institute is an encouraging sign that there is an increasing demand for information and a growing interest in the working environment.

The first part of the report is devoted to an important milestone in the life of the Institute-the opening of the new department by HRH the Queen Mother.

There follows a review of the work of the Institute in four fields:

1. The Information Service: By far the greatest individual users are the Trade Unions, but management, occupational health nurses, and universities are also seeking advice in increasing numbers.

2. An Investigational Service giving a service to industry in a wide variety of problems. Despite all the knowledge and published work on the subject, lead still remains one of the most pressing problems. Technology is seeking new and improved ways in which a reliable and manageable test be readily available for estimating the body burden of lead among large numbers of exposed persons and its predictable effect on health. The newest technique of atomic absorption spectrometry may offer this solution but the technical difficulties of obtaining uncontaminated samples still prejudice the accuracy of results.

3. Teaching of occupational health occupies much of the time of the Institute.
This is directed not only at postgraduate students with a medical or scientific background but also at nurses and medical students.

A highly commendable activity is their liaison with the mass media in an effort to provide the general public with informed opinion.

4. Research into a wide variety of hazards, such as back injuries in dock workers, and protective clothing in the notoriously hazardous fishing industry, are described as well as more familiar hazards such as lead, mercury, and asbestos.

The final pages are devoted to the income and expenditure accounts which demonstrate the high cost of running such a service and the difficulties in extracting appropriate fees for services rendered. Were it not for substantial subsidies from The London School of Hygiene and the TUC the service would find it difficult to survive.

It is to be hoped that public demand for safe and healthy workplaces, and indeed the safety of the public itself in its homes, on the roads, etc., will make the Institute less dependable on subsidies in the near future.

It would be helpful if more annual reports were available from similar organizations to highlight progress in the occupational health field.

\section{R. A. TReVethick}

National Coal Board Medical Service Annual Report 1971-72. (Pp. 32; £1.00.) London: National Coal Board. 1973.

The British industrial medical officer may often feel frustrated by the limitations which custom and etiquette impose on his freedom to investigate or treat the illnesses which he diagnoses. His role is primarily preventive, and if any justification were needed for this approach it is given by the Annual Report of the National Coal Board Medical Service. This report gives details of the virtual elimination of Weil's disease and nystagmus, and of very substantial progress in the battle against beat disease. Tenosynovitis does not present such a satisfactory picture, while dermatitis has so far resisted all efforts at prevention.

Opinions may differ on the disability attributable to pneumoconiosis, but its prevalence is a useful biological monitor of the effectiveness of dust control. The report gives the results of surveys carried out between 1969 and 1971 and compares them with previous surveys. One should not expect rapid change in a condition which is so slow to evolve but the prevalence rate has fallen in all areas, except East and West Wales; even in these areas there has been a fall in prevalence among the younger miners. The report is, in my view, unnecessarily gloomy about pneumoconiosis; the unsatisfactory picture presented by the table of Progression Indices is probably attributable to increasing age of the men over these 10 years, pneumoconiosis being an age-related condition.

It is too early yet to expect any benefit from the new gravimetric standards used in dust control, which came into use in 1970, but details are given of substantial progress in this field. It seems that development work (drivages) in stone now presents the greatest problem in the control of dust.

The Report is well written and attractively produced but it is a disappointment to find that it no longer includes 